\section{Perspectiva da epistemologia histórica e a escola promotora de saúde}

\section{Perspective of historical epistemology and health promotion in schools}

João Batista Vianey Silveira Moura

Pedagogo, mestre em Educação em Saúde pela Universidade de Fortaleza - Unifor

Rua Dr. Joaquim Frota, 395 Seis Bocas 60833-430 Fortaleza - CE - Brasil jbatista2001@terra.com.br

Lídia Andrade Lourinho

Fonoaudióloga, mestre em Educação em Saúde pela Unifor Rua Efésio, 578 Cocó

60811-180 Fortaleza - CE - Brasil lidia.lourinho@ig.com.br

\section{Maria Teresa Moreno Valdês}

Psicóloga, professora do Curso de Fonoaudiologia e do Mestrado em Educação em Saúde da Unifor Rua Tenente Amauri Pio, 99 apto. 1, Meireles 60160-090 Fortaleza - CE - Brasil maitemoreno19@yahoo.es

Mirna Albuquerque Frota

Enfermeira, professora do Curso de Enfermagem e do Mestrado em Educação em Saúde da Unifor Rua Manuel Jacaré, 150 apto. 1401 - Meireles

60175-110 Fortaleza - CE - Brasil mirnafrota@unifor.br

Ana Maria Fontenelle Catrib Pedagoga, professora do Curso de Pedagogia e do Mestrado em Educação em Saúde da Unifor

Rua Paula Ney, 77 apto. 1100 Aldeota 60.125-120 Fortaleza - CE - Brasil catrib@unifor.br
MOURA, João Batista Vianey Silveira; LOURINHO, Lídia Andrade; VALDÊS, Maria Teresa Moreno; FROTA, Mirna Albuquerque; CATRIB, Ana Maria Fontenelle. Perspectiva da epistemologia histórica e a escola promotora de saúde. História, Ciências, Saúde - Manguinhos, Rio de Janeiro, v.14, n.2, p.489-501, abr.-jun. 2007.

Aborda-se a educação, especificamente a escola na perspectiva filosófica de Gaston Bachelard e Thomas Kuhn, bem como nos aspectos da promoção da saúde. Critica-se a escola instrumentalista, mostrando que esse modelo chegou à exaustão. Faz-se uso da abordagem bachelardiana, na perspectiva de que todo conhecimento é resultado de minucioso trabalho de interrogação da realidade. A partir das idéias de Kuhn, refletese sobre a mudança de paradigmas e o seu significado nos espaços educacionais. Com base nessas duas vias, discute-se o projeto da escola desejada: inclusiva, múltipla, pluralista, interativa e sistêmica, que promova a saúde, perceba a natureza como fonte de vida e discuta as relações do ambiente sob a ótica da bioética, da qualidade de vida e da cidadania.

PALAVRAS-CHAVE: epistemologia; educação em saúde; promoção de saúde na escola.

MOURA, João Batista Vianey Silveira; LOURINHO, Lídia Andrade; VALDÊS, Maria Teresa Moreno; FROTA, Mirna Albuquerque; CATRIB, Ana Maria Fontenelle. Perspective of historical epistemology and health promotion in schools. História, Ciências, Saúde - Manguinhos, Rio de Janeiro, v.14, n.2, p.489-501, Apr.-June 2007.

This article discusses education, especially school itself, from the philosophical perspective of Gaston Bachelard and Thomas Kuhn, along with some aspects of healthcare. A criticism is made of instrumentalism in school, showing how this model has been exhausted. Recourse is made to the thinking of Bachelard, whereby all knowledge is the result of the painstaking work of investigating reality. The ideas of Kuhn are drawn upon to reflect on the paradigm shift and its meaning in education. Based on these two lines, the design of a desirable school is put forward: inclusive, multiple, pluralist, interactive, systematic, promoting health, perceiving nature as a source of life, and discussing the relationship with the environment from the perspective of bioethics, quality of life and citizenship.

KEYWORDS: epistemology; health education; promoting health at school. 
A proposta central deste artigo é tecer uma reflexão sobre a prática educativa que se estabelece no espaço escolar. Optou-se, portanto, por discutir o modelo de escola que predomina na sociedade, conservador e reprodutor, pois esta é a escola que historicamente vem se prestando à perpetuação da ordem vigente. Ressaltase que as mudanças aceleradas produzem impactos gigantescos no espaço escolar, gerando uma crise que se expressa em múltiplos aspectos, entre os quais os de valores morais, individualismo, pouca disciplina para o estudo e desmobilização do jovem. E não se podem desconsiderar, hoje, os graves problemas planetários, como fome, exclusão social, guerras e desastres ecológicos. Ou seja, trata-se de um modelo de escola que não responde mais às expectativas geradas pelas intensas transformações de ordem social, política, econômica e cultural.

Na cultura moderna, a escola é marcada pela transmissão do conhecimento, internalização de condutas e construção de habilidades específicas, e por conferir distinções culturais e privilégios profissionais. É, ao mesmo tempo, a escola dos ritos, tais como disciplina, carga horária/grade curricular, rigidez de estruturas - esforço de manutenção do ambiente nitidamente tradicional, encarregado mais de reproduzir que de recriar e reconstruir. Percebe-se um descompasso entre a instituição e seus atores. A escola pode caminhar para a acomodação ou afirmar a urgência de superar a crise.

A escola na sociedade pós-moderna vem a reboque da rápida marcha evolutiva, procurando adequar-se para atender aos imperativos da engrenagem econômica que se movimenta de maneira implacável e da revolução tecnológica que, em lugar de nos servir, pode, ao contrário, promover a alienação.

Portanto, a crise do paradigma mecanicista cartesiano e newtoniano, ainda profundamente enraizado, deu espaço para o avanço de uma visão holística e ecológica que convida a ver e analisar a realidade valendo-se de novas fundamentações, calcadas na concepção de desenvolvimento da própria mudança científica (Gutiérrez et al., 1999; Capra, 1995).

A visão ecológica permite considerar o mundo do ponto de vista das relações e integrações e não com base em situações isoladas. Boff (1996) considera que essa forma de ver o mundo supõe novos modos de ser, sentir, pensar, valorizar e agir que trazem novos valores e comportamentos que influenciam um número cada vez maior de pessoas e de comunidades.

$\mathrm{O}$ paradigma que presidiu o agir até o momento atual vive a crise mais aguda, sua lógica é fundamentada no racionalismo que despreza a subjetividade, enquanto apregoa o desenvolvimento e o progresso em detrimento da natureza e da vida no planeta (Gutiérrez, Prado, 1999). Esse paradigma influenciou e ainda influencia profundamente a educação mas, ao mesmo tempo, como 
afirma Santos (2005), a caracterização da crise do paradigma dominante traz consigo o perfil do paradigma emergente.

Nesta perspectiva, a crise no paradigma atual da educação demarca a transição de visões e concepções que orientam o novo pensar e agir no âmbito político, econômico, cultural e educativo. As propostas que interessam à educação são as ligadas ao desenvolvimento sustentável, à formação de uma cidadania planetária, como defendem Morin e Kern (1995), e à criação e promoção da cultura da sustentabilidade.

Nesse sentido, considera-se como escola-modelo aquela que é, ao mesmo tempo, espaço de construção da liberdade, do saber, da cidadania e da superação das relações autoritárias; aquela, enfim, capaz de promover a cultura da solidariedade. Para tanto, desenvolve-se uma reflexão à luz do pensamento de Gaston Bachelard e Thomas Kuhn, o primeiro, professor de matemática nascido na França e adversário incansável das idéias positivistas, e o segundo, um físico teórico nascido nos Estados Unidos, que enveredou pelo estudo da história das ciências e escreveu sobre as estruturas das revoluções científicas, elaborando a teoria sobre as mudanças de paradigmas. Como suas idéias marcaram o conhecimento científico, este trabalho visa realizar uma transposição delas para o campo da educação.

Sabe-se, no entanto, que a fragmentação, a despersonalização e a desmotivação são situações verificadas no espaço que deveria ser construtivo. Tendo em vista estas preocupações, faz-se necessário buscar o ponto de ruptura com a velha ordem escolar, superada, dicotômica e positivista. Bachelard, ao pensar o sentido histórico das ciências, visualizava o mundo como um imenso palco onde o conhecimento configurava-se como o trabalho de interrogação da realidade. Para Kuhn, quando há uma mudança de paradigma, muda-se a maneira de olhar o mundo. Os pensamentos de Bachelard e Kuhn superaram os muros da ciência e invadiram o contexto da realidade social. A práxis escolar vinculada à práxis social mais ampla não poderia deixar de sentir os impactos dessas idéias, pois a escola é uma instituição construída por pessoas, daí o seu caráter histórico.

\section{A escola e o enfoque epistemológico: Bachelard e Kuhn}

A reflexão surge a partir de duas perspectivas: a bachelardiana, que, compreendendo a falibilidade do conhecimento, ao mesmo tempo estabelece seu caráter filosófico e histórico e busca vinculá-lo aos fenômenos da educação; e a kuhniana, um dos momentos mais significativos das revoluções do pensamento científico, que corresponde à análise do papel dos fatores exteriores à ciência na irrupção de momentos de crise e transformação do pensamento cien- 
tífico e da prática correspondente. Sua grande contribuição consiste em apontar a mudança de paradigma, que constitui uma referência para um projeto que propicie a superação do mecanicismo encravado na escola.

De acordo com Bachelard (1996), para um espírito verdadeiramente científico todo conhecimento é uma resposta a uma pergunta, ou seja, é resultado de um exaustivo trabalho de interrogação da realidade. Desta forma, três conceitos são fundamentais na história das ciências: o de obstáculo epistemológico, o de dialética e o de um novo espírito científico.

Com a idéia de obstáculo epistemológico procura-se dar relevância aos erros surgidos ao longo do processo científico, omitidos ou desconhecidos pela história tradicional. O erro faz surgir a verdade e, como conseqüência, uma autêntica história das ciências. Um dos primeiros obstáculos a serem ultrapassados é a opinião, pois também um fato mal interpretado torna-se um empecilho para o epistemólogo. Outro exemplo de obstáculos epistemológicos são aqueles que ocorrem quando uma marcha progressiva de organização do conhecimento vê-se ameaçada por novas descobertas.

Paralelamente ao conceito de obstáculo epistemológico tem-se a dialética, isto é, a superação de partes da história e sua validação pela ciência atual. A dialética não se orienta propriamente pela morte do passado. Nega-se a continuidade grosseira, ingênua da história. Assim, para Bachelard, seria mais interessante falar no par contínuo-descontínuo, do que consagrar um dos elementos e condenar o outro. Organizar o saber científico é reconhecer que o próprio processo histórico é capaz de possibilitar o 'ajustamento' entre teoria e prática, admitindo, portanto, que a ciência é progressiva e resulta de um acréscimo do saber e de uma acumulação de conhecimentos, como afirma Bachelard (1996).

O novo espírito científico bachelardiano pode ser mais bem conhecido por meio dos princípios dominantes nessa nova atitude intelectual, que são: precisar, retificar e diversificar. Portanto, a cada verdade encontrada urge questionar, interrogar cada vez mais. Assim o saber tradicional perde a característica de estático, fechado, sendo substituído pelo conhecimento dinâmico que foge à certeza e a unidades dogmáticas, que podem vir a ser autênticos obstáculos epistemológicos.

O propósito de Bachelard não é legitimar a ciência, a qual o filósofo não aceita como algo originalmente dado, e sim reconstruir passo a passo essa ciência que é produto de um processo e de uma prática histórica. Queremos lançar mão do pensamento bachelardiano e transpor a noção de obstáculo epistemológico para a prática da educação, objeto de reflexão deste estudo. Como afirmam Barreto e Moreira (1997), na educação, muitas vezes, o obstáculo é do tipo pedagógico e está relacionado à não-investigação do 
erro por parte dos professores, que não mudam a experiência cultural de seus alunos, nem desenvolvem a própria cultura mediante formação continuada em conteúdo e método.

A relevância da epistemologia histórica para a educação é defendida por Wachowicz (2006), que afirma o caráter histórico da educação escolar e a construção na escola do sujeito científico da educação, definido como "uma cultura existente e referente a uma determinada área da ciência, nesse caso a educação" (p.382).

É válido ressaltar a forte presença do cientificismo e da reprodução memorística na prática escolar. Além disso, não se tem promovido o espírito criativo e imaginativo necessário ao desenvolvimento do pensamento divergente, da multiplicidade das idéias e até mesmo da ousadia. Esta dimensão teria o significado no ousar, pensar, criar, imaginar, construir, ser e aprender com os próprios erros, assim confirmando o que Bachelard ressalta com o aprender com os próprios erros e observar que nada é gratuito, tudo é construído.

Portanto, o cientificismo e a reprodução excessiva dos conteúdos são exageros cometidos pela escola, reduzindo a percepção da história à aceitação de 'verdades' e à repetição do passado. São um obstáculo epistemológico a ser superado, pois acredita-se em uma escola que pulsa e vibra, que produz e promove a vida em todas as dimensões. Outra proposição é a do binômio contínuo-descontínuo, por cujo enfoque percebe-se o jogo das contradições e afirma-se a descontinuidade da história. A escola, do mesmo modo, em lugar de ser apenas contínua, deve superar-se a cada momento e permitir novas idéias, conflitos e contradições.

Com o propósito de aprofundar a reflexão, destacamos a prática escolar na ótica de Thomas Kuhn (1922-1996), que desenvolveu estudos de história da ciência e filosóficos. Os paradigmas exercem influência em todas as ciências. Quando fatos não mais se coadunam aos paradigmas vigentes, acontecem anomalias que levam à criação de novos paradigmas. Segundo Kuhn (2001), crises de paradigma ocorrem quando a pesquisa, em determinada situação, não alcança os resultados esperados, podendo-se dizer que a natureza violou as expectativas. Anomalias podem também determinar uma modificação no paradigma ou apenas contribuir para isso. A crise do paradigma atual de educação, e particularmente da escola, leva à proposição de novos caminhos.

Pácios e Rossa (2002) comentam que a nova visão da física quântica, biologia, biogenética e de outros ramos do saber humano está incitando a humanidade a superar os paradigmas fragmentados e limitantes do conhecimento e a buscar alternativas que contemplem questões da globalidade/centralidade da vida. Assim, surge a necessidade de reflexão sobre novos paradigmas/modelos de educação, em cujo centro não mais esteja o mercado e a competição, e sim a relação solidária humanidade/natureza, a ética, a espiritualidade e a vida. 
O paradigma é uma visão de mundo; no que concerne à educação, a forma de abordá-la dependerá dos paradigmas com que trabalhará o estudioso (Wachowicz, 2006). Na nossa perspectiva, a escola a ser construída não se compatibiliza com o modelo mecanicista e compartimentado que hoje vigora. A visão de escola por nós defendida é inclusiva, pois se percebe o mundo em suas múltiplas relações e interações. Dessa forma, imagina-se uma escola envolvida em uma ampla rede de conexões, sistêmica, promotora do ser humano, que perceba a natureza como fonte de vida e discuta as relações do/no ambiente sob a ótica da bioética.

O modelo mecanicista, fragmentado e compartimentado, não consegue dar respostas aos problemas e às angústias da humanidade. A escola sofre os impactos das mudanças políticas, sociais, econômicas e tecnológicas, e mesmo assim resiste às mudanças, pois é uma instituição que carrega consigo o fardo do conservadorismo. Por isso, essa instituição é conflituosa. Como, estando inserida no núcleo das mudanças, pode resistir a elas? Em seu método dialético, Kuhn mostra-nos que o estudo dos paradigmas é formado do conflito dos contrários. Os contrastes estão interligados. Parafraseando-o, teríamos: a escola seria a tese, a crise da escola a antítese, o resultado a síntese. Tal método de procedimento é históricodiscursivo e mostra como os paradigmas se formam e entram em crise, forçando a criação de outros novos. Dessa maneira, a crise da escola que presenciamos hoje surge do questionamento do paradigma tradicional, que entrou em crise e já aponta para o surgimento de outro, capaz de solucionar os novos obstáculos.

\section{A escola promotora de saúde}

As reflexões aqui indicadas nos auxiliam a formular uma proposta de escola que invista na promoção do ser humano na sua totalidade. Assim é que a idéia de promoção da saúde vem sendo debatida em todo o planeta, na perspectiva de melhoria das condições de saúde. Discussões sobre educação e promoção da saúde poderão evoluir para a operacionalização de programas que possibilitem o aumento da qualidade de vida dos povos. Para Czeresnia e Freitas (2003), a promoção envolve o fortalecimento da capacidade individual e coletiva para lidar com a multiplicidade dos condicionantes da saúde, por meio do estímulo à capacidade de escolha, bem como à utilização do conhecimento com o devido discernimento de diferenças e singularidades dos acontecimentos.

Ressalta-se, portanto, a relação entre a epistemologia histórica, a promoção de saúde e a escola promotora de saúde. Wachowicz (2006) refere-se à necessidade de se fazer uma ponte entre os conhecimentos das ciências exatas e os das ciências humanas e da saúde. Complementa que a partir do pressuposto de que o projeto da edu- 
cação escolar é histórico e específico a cada sociedade, assim como é construído no cotidiano das instituições de ensino, das salas de aula, entre outros, também o sujeito científico da educação escolar é exatamente o conjunto dessas vivências, consideradas complexas e diversificadas.

Diversas conferências internacionais na área de saúde defendem a idéia de promoção como um paradigma alternativo para as políticas de saúde em todos os países. Os compromissos e orientações que servem de base para a promoção da saúde e educação em saúde no âmbito escolar, segundo Ippolito-Shepherd (2002), foram definidos em eventos que produziram os seguintes documentos: Carta de Ottawa (1986), Declaração de Adelaide (1988), Declaração de Sundsvall (1991), Declaração de Bogotá (1992), Conferência do Caribe (1993), Declaração de Jacarta (1997) e Declaração do México (2000).

Esse movimento histórico busca desenvolver o potencial humano e ambiental. Conforme a Carta de Ottawa, a promoção da saúde consiste em proporcionar à população condições e requisitos necessários para melhorar as condições de saúde e exercer o controle sobre elas, entre as quais encontram-se a paz, educação, moradia, alimentação, renda, um ecossistema estável, justiça social e eqüidade. A promoção da saúde requer articulação, parceria, integração e fortalecimento dos vínculos homem/natureza. Para concretizá-la é necessário mobilizar esforços individuais e coletivos, bem como articular múltiplas dimensões da sociedade: cultural, econômica, social e política. Isto define o caráter multidisciplinar da educação em saúde.

A promoção da saúde é considerada uma combinação de apoios educacionais e ambientais que visam atingir ações e condições de vida conducentes à saúde. Desde o final do século passado, representa uma estratégia para enfrentar os múltiplos problemas de saúde que afetam as populações humanas e seus entornos. Para o processo saúde-doença, a promoção da saúde propõe a articulação de saberes técnicos e populares, e a mobilização de recursos institucionais e comunitários, públicos e privados (Candeias, 1997; Buss, 2000).

O cuidar, nessa visão complexa, que emerge da concepção do ser humano como um sistema aberto e vivendo em rede, implica abordar a promoção da saúde numa perspectiva transdisciplinar. Na ótica da transdisciplinaridade, o homem não pode mais ser visto de forma fracionada, estudadas parcialmente por disciplinas pontuais ou simplesmente justapostas, exigência da inter e da multidisciplinaridade. No arcabouço científico deste novo milênio, essa exigência soa como óbvia, porém só existe o mundo em que todos estão inseridos é apenas um, e este é um todo maior que a soma de suas partes (Boff, 2004; Morin, 2001; Morin e Kern, 1995; Nicolescu, 2000). Sendo assim, concebemos a educação e a promoção em saúde 
estabelecendo entre elas estreitos vínculos. À primeira corresponde o eixo estratégico para a promoção da saúde, no que se refere ao desenvolvimento humano e por conseqüência ao da sociedade. Criar articulações entre esses dois eixos possibilita a otimização de recursos que visam à melhoria do bem-estar de crianças e adultos que fazem parte da comunidade educativa.

As 'escolas promotoras de saúde' constituem uma iniciativa de caráter mundial que tem como antecedente a Rede Européia de Escolas Promotoras de Saúde, articulada pela Organização Mundial da Saúde (OMS) em 1992. Foram lançadas pela Organização PanAmericana da Saúde (OPAS)/OMS na região da América Latina e do Caribe em 1995, com o objetivo de fortalecer e ampliar a colaboração entre os setores de saúde e educação nas práticas de saúde escolar, incluindo apoio e cooperação dos pais e da comunidade e impulsionando políticas na comunidade escolar. Portanto, facilitam o planejamento estratégico e a execução de programas na escola, abrangendo educação em saúde e capacitação em habilidades para estilos de vida e comportamentos sadios, criação e desenvolvimento de ambientes saudáveis, provisão de serviços de saúde e alimentação, assim como promoção de uma vida ativa (Cerqueira, 2002). Tais objetivos foram referendados na Política Nacional de Promoção da Saúde (Brasil, 2006), em suas ações específicas para o biênio 20062007, nas quais se destaca a necessidade de articular, com o Ministério de Educação e as secretarias municipais e estaduais, a promoção da saúde no ambiente escolar. Dessa forma, a escola promotora de saúde deve ser interativa e dinâmica em suas dimensões física, social, ecológica, comunitária e educativa, visando desenvolver políticas e práticas que propiciem mudanças de atitudes no que se refere a ações saudáveis no espaço escolar. Assim, acredita-se que a promoção da saúde é um processo em desenvolvimento permanente e que tanto o processo educativo como o de promoção da saúde contribuem para o desenvolvimento de capacidades, aquisições e competências de cada indivíduo e da comunidade, com o objetivo central de desenvolver hábitos saudáveis e possibilitar o pleno exercício da cidadania (OMS, 1996; Morgan, 2002; Ippolito-Shepherd, 2002).

Qual é o papel da escola, no desenvolvimento de estratégias educativas de promoção da saúde? Inicialmente, a escola pode se despojar de todo o fardo cartesiano e positivista e começar a perceber-se como espaço de humanização e promoção de qualidade de vida. Para tanto é necessário que a concepção ecológica de educação e de escola tome o lugar da concepção instrumentalizada e mercadológica. A crise em que se encontra a escola já nos autoriza a apontar para essa mudança de paradigma.

O que viria a ser tal concepção ecológica de educação? Na dimensão ecológica de educação e de escola, o ser humano ocupa lugar central e é visto como fim de todo esforço educativo. $\mathrm{O}$ desen- 
volvimento sustentável humanista constitui o ambiente propício a essa construção. Ele tem a missão de substituir a mentalidade instrumental, utilitarista e predadora no uso da natureza, por uma cultura de respeito e cuidado. Bordenave e Rocha (2002) elencam as principais características da pedagogia da dimensão ecológica da educação: aproximação da vida real, interdisciplinaridade curricular e pedagogia problematizadora, marcada pelo caráter dialético, que mantém a mentalidade aberta, flexível e integrada.

A concepção eco-pedagógica da educação estabelece estreitos vínculos com as práticas educativas em saúde, quando concebe a promoção da aprendizagem como um dos princípios fundamentais da educação. Para Gutiérrez e Prado (1999), a pedagogia consiste no trabalho de promoção da aprendizagem na vida cotidiana, por meio de todos os recursos colocados à disposição no ato educativo. Os autores reiteram que as pessoas se realizam como seres humanos quando conseguem conquistar e trabalhar os espaços de aprendizagem na cotidianidade.

Gutiérrez e Prado (1999) afirmam também que promovemos a mentalidade eco-pedagógica da educação quando defendemos a vida baseada na cotidianidade; a ação ética; a integridade da natureza por meio do desenvolvimento economicamente viável, socialmente justo e ambientalmente adequado; as oportunidades de compartilhar experiências, desejos, interesses, afetividade, aspirações e preocupações; a visão integral, tanto do mundo como do ser humano; um sistema de vida integrado, dinâmico e inteligente, que proporcione uma compreensão viva, dinâmica e planetária. $\mathrm{O}$ ambiente escolar, nessa perspectiva, passa a ser concebido como espaço de convivência e intensas interações sociais, apresentando-se, portanto, como um terreno fértil para implementação das propostas, estratégias e ações que envolvem promoção de saúde numa dimensão eco-pedagógica.

Ressalta-se, assim, que a proposta da escola promotora de saúde está diretamente vinculada e articulada à dimensão ecológica de educação, assim como contribui para desenvolver aspectos almejados nos relatórios das Cartas de Promoção da Saúde e do Plano de Ação 2003-2012 da Iniciativa Regional Escolas Promotoras de Saúde, quais sejam: desenvolver habilidades pessoais; estimular diálogo entre os diferentes saberes; oferecer oportunidades para a conquista da autonomia; propiciar condições para analisar a realidade e identificar fatores determinantes de saúde; capacitar o controle sobre a condição de saúde; fornecer conhecimentos e instrumentos para libertação e mudança; intensificar suportes sociais e reforçar a ação comunitária; mobilizar e motivar o compromisso social e político, redefinindo papéis e responsabilidades.

Quando combatemos a visão mecanicista e mercantilizada à qual está sujeita a prática escolar, queremos dizer 'não' às formas 
de instrumentalização do saber que têm servido para dominar, submeter, depredar e exaurir. Ao mesmo tempo, edificar a escola formadora de mulheres e homens comprometidos com o respeito e a promoção da vida, concentrando esforços na construção de uma consciência ecológica. Nesse sentido, Correia (2002, p.68) afirma:

Tal consciência parte do princípio de que o bem-estar da humanidade depende da preservação dos sistemas ecológicos, da rica variedade de plantas e animais, solos férteis, águas puras e ar limpo. Preservar a biosfera é mantê-la saudável; é protegê-la em sua vitalidade, diversidade e beleza. Esse é um dever sagrado do ser humano, parte consciente dessa bolha que é o nosso planeta.

Concebemos uma escola promotora de saúde que desenvolva uma mentalidade eco-pedagógica da educação. Portanto, para participar e atuar em qualquer mudança, a escola deve buscar a consolidação da promoção da saúde no espaço escolar por intermédio do compartilhamento, entre educadores e educandos, de experiências da realidade social. O objetivo maior é sensibilizar todos na busca de saúde de grupos e de toda a coletividade, reforçando assim a ação comunitária através de redes sociais de apoio, do desenvolvimento de aptidões pessoais e do estímulo ao exercício da cidadania, ações estas que concretizarão a promoção da saúde no espaço escolar.

Que práticas a escola poderá adotar, para a promoção da saúde? Barroso,Vieira e Varela (2003) propõem alguns princípios norteadores das práticas sociais de educação em saúde e da escola promotora de saúde: o reforço ao sujeito social para capacitá-lo a cuidar de si e agir em grupo na defesa da promoção da saúde; a valorização da subjetividade e intersubjetividade no processo de conhecimento da realidade, privilegiando o diálogo como expressão da comunicação; o estímulo à participação; a utilização de estratégias que permitam a coexistência da interface de várias áreas do conhecimento; o reconhecimento da dimensão afetiva no processo de transformação; o incentivo e fomento de avanços e parcerias por meio de redes sociais de apoio. Esses princípios são condizentes com os estabelecidos no Plano de Ação 2003-2012 da Iniciativa Regional Escolas Promotoras de Saúde (Ippolito-Shepherd, 2002). Todos eles concorrem para a aceitação de que práticas educativas na escola devem ir além de ações pedagógicas e possibilitar transformações individuais e sociais, contribuindo assim para a formação de sujeitos éticos e cidadãos em busca constante de uma vida melhor. Para Lima,Catrib e Vieira (2004), a questão da formação dos educadores deve ser considerada prioritária para as metas governamentais, e a colaboração de pesquisadores e intelectuais indicando caminhos epistemológicos é de vital importância. 
O ambiente escolar, como espaço de convivência e intensas interações sociais, apresenta-se como um terreno fértil para implementação de propostas, estratégias e ações que envolvem promoção de saúde. A questão tem apresentado, ao longo do tempo, diversas significações. No que concerne à sua função social, na escola desenvolvem-se processos educacionais que articulam ações de naturezas diversas, as quais, extrapolando o território escolar, alcançam o espaço comunitário. De fato, durante o século XX, políticas educativas em saúde encontraram na escola suporte para o desenvolvimento de programas, ainda que de caráter prescritivo, centrados no modelo biomédico, nos hábitos higiênicos e morais e no uso da pedagogia tradicional.

A saúde tem estado presente nos objetivos curriculares e permeia todas as atividades escolares. Segundo Catalán (2001), podem ser consideradas estratégias e ações a serem necessariamente adotadas em uma escola promotora de saúde: utilizar-se do diálogo na resolução de problemas; desenvolver as capacidades necessárias para identificação dos fatores de risco no trabalho; evitar situações constrangedoras e não recorrer à coerção e punição como instrumento educativo; estar atento, na elaboração da estrutura curricular, à adequação de conceitos, habilidades e atitudes que permitam realizar ações individuais e coletivas que melhorem a qualidade de vida e favoreçam as relações interpessoais; disponibilizar veículos de expressão para todas as pessoas que convivem na escola; proporcionar programas ergonômicos que privilegiem cuidados com o corpo e a mente e desenvolver atividades que envolvam comunidade educativa e família.

\section{Conclusão}

Procuramos defender a pertinência das idéias de Bachelard e Thomas Kuhn na esfera da educação. Embora não tenham desenvolvido teorias relacionadas diretamente a práticas educativas na escola, os dois pensadores voltaram suas reflexões para o pensamento científico, abordando a história da ciência e a mudança de paradigma. E em suas discussões dão suporte teórico e filosófico para o desenvolvimento de uma visão de ciência que se estende por múltiplas áreas e saberes.

Não mais educamos para certezas, mas sim para incertezas. Podemos aprender bastante com os erros, como afirma Bachelard, pois a noção de falibilidade das teorias nos permite desenvolver um movimento constante de questionamento e problematização da realidade. Construímos a escola que queremos ao questionar seu status quo e problematizar seu modelo atual, que consideramos superado. Assim sendo, apontamos para uma mudança paradigmática pois, como comenta Thomas Kuhn, "a transição para um novo paradigma 
é uma revolução científica". Nesta perspectiva, a transição para um novo paradigma de escola, que seja promotora da ecologia e da saúde, proporcionará uma revolução educacional de repercussão em escala planetária.

\section{REFERÊNCIAS BIBLIOGRÁFICAS}

Bachelard, Gaston 1996

Barreto, José Anchieta Esmeraldo; Moreira, Rui Verlaine Oliveira (Org.)

\section{7}

Barroso, Maria Grasiela Teixeira; Vieira, Neiva Francenely C.;Varela,

Zulene Maria de V. 2003

Boff, Leonardo 2004

Boff, Leonardo 1996

Bordenave, Juan Diaz; Rocha, Paulo Diaz 2002

Brasil 2006

Brasil 1996

Buss, Paulo Marchiori 2000

Candeias, Nelly Martins Ferreira 1997

Capra, Fritjof 1995

Cerqueira, Maria Tereza 2002

Correia, João Luís 2002

Czeresnia, Dina; Freitas, Carlos Machado de (Org.) 2003
A formação do espírito científico.

Rio de Janeiro: Contraponto.

Imaginando erros.

Fortaleza: Casa José de Alencar/Programa Editorial.

Educação em saúde: no contexto da promoção humana. Fortaleza: Ed. Demócrito Rocha.

Saber cuidar: ética do humano - compaixão pela terra. Petrópolis: Vozes.

Ecologia: grito da terra, grito dos pobres. São Paulo: Ática.

A dimensão ecológica da educação.

Revista de Educação, Brasília, v.31, n.122, p.34.

Ministério da Saúde. Política Nacional de Promoção da Saúde. Brasília: n.d. Documento para discussão.

Ministério da Saúde. Promoção da Saúde - Carta de Ottazua, Declaração de Adelaide, Declaração de Sunsvall, Declaração de Bogotá. Brasília: n.d.

Promoção da saúde e qualidade de vida.

Ciência E Saúde Coletiva, Rio de Janeiro, v.5, n.1, p.163-177.

Conceitos de promoção em saúde: mudanças individuais e mudanças organizacionais. Revista de Saúde Pública, São Paulo, v.31, n.2, p.209-213.

O ponto de mutação.

São Paulo: Cultrix.

Promoción de la salud en la región de las Américas. In: Memorias III Reunión Latinoamericana de Escuelas Promotoras de la Salud. Quito: OPAS.

A escola como fórum de ecologia.

Revista de Educação AEC, Brasília, v.31, n.122, p.68.

Promoção da saúde: conceitos, reflexões, tendências. Rio de Janeiro: Fiocruz. 
Gavidia Catalán, Valentín

2001

Gutiérrez, Francisco; Prado, Cruz

1999

Ippolito-Shepherd, Josefa 2002

Kuhn, Thomas Samuel

Lima, Maria Adiléia F.; Catrib, Ana Maria F.; Vieira, Luiza Jane E. de Souza

2004

Morgan, Paula 2002

Morin, Edgar

Morin, Edgard; Kern, Anne Brgitte 1995

Nicolescu, Basarab 2000

OMS 1996

Pácios, Amábile ; Rossa, Leandro 2002

Santos, Boaventura de Souza 2005

Wachowicz, Lílian Anna 2006
La transversalidad y la escuela promotora de salud.

Revista Española de Salud Pública, Madrid, v.6, n.75, p.505-516.

Ecopedagogia e cidadania planetária.

São Paulo: Cortez.

Plan de Acción 2003-2012 - Iniciativa Regional Escuelas Promotoras de la Salud. In: Memorias III Reunión Latinoamericana de Escuelas Promotoras de la Salud. Quito: OPAS.

A estrutura das revoluções científicas.

São Paulo: Perspectiva.

Compreensão existencial: uma abordagem pedagógica de promoção da vida. História, Ciências, Saúde - Manguinhos, Rio de Janeiro, v.11, n.2, p.297-319.

La iniciativa global de salud escolar de la OMS: un esfuerzo global para ayudar a escuelas a convertirse en Escuelas Promotoras de la salud. In: Memorias III Reunión Latinoamericana de Escuelas Promotoras de la Salud. Quito: OPAS.

Os sete saberes necessários à educação do futuro. São Paulo: Cortez.

Terra pátria.

Porto Alegre: Sulina.

Manifesto da transdisciplinaridade. Brasília: Unesco.

Organização Mundial da Saúde. Escolas Promotoras de Saúde: modelo e guia para a ação. Washington, (D.C.): Opas. (Série HSS/Silos.)

Resenha.

Revista de Educação AEC, Brasília, v.31, n.122, p.5.

A crítica da razão indolente: contra o desperdício da experiência.

São Paulo: Cortez.

Fundamentos epistemológicos da pesquisa em aprendizagem e avaliação, na educação escolar. In: Silva, Aida Maria Monteiro et al. (Org.) Educação formal e não formal, processos formativos, saberes pedagógicos: desafios para a inclusão social. Recife: Endipe. p.379-400.

Recebido para publicação em setembro de 2005.

Aprovado para publicação em agosto de 2006. 